\title{
On the Occurrence of Cellulose in the Xylem of Woody Stems.
}

\author{
BY
}

\author{
M. C. POTTER, M.A.,
}

Professor of Botany in the University of Durham College of Science, Newcastle-upon-Tyne.

\section{With Plate VIII.}

THE appearance of cellulose in the xylem of various trees when attacked 1 by certain wood-destroying Fungi has been noted, and has been attributed to the action of a delignifying enzyme secreted by the Fungi. Hartig ('78), in his classic work upon the destruction of the wood of Conifers and of the Oak by certain Fungi, has given an account of the appearance of cellulose in the wood when under the influence of such attack. In the Oak, he describes in detail the special action upon the wood of Telephora perdix, Polyporus ignarius, P. dryadeus, and Stereum hirsutum, and states in each case that in the process of decay the lignified walls become converted into cellulose, attributing this change to the delignification by the hyphae. In the wood of the Conifers the same appearance is noted and ascribed to the influence of Trametes and other Fungi.

Mayr ('84) attributes the presence of cellulose in the stem of Betula to the action of the parasitic Fungi Polyporus betulinus and P. laevigatus.

Marshall Ward ('97), studying the action of Stereum hirsutum upon the wood of Aesculus, has demonstrated the presence of cellulose in the xylem when infected by a pure culture of this Fungus. The swollen inner layers of the cell-wall become delignified and consist entirely or almost entirely of cellulose, as shown by the differentiating colour-tests of chlorzinc-iodine, and phloroglucin. The hyphae attack the walls of the tracheides and other wood-elements, and, he considers, gradually delignify them from the lumen outwards. Marshall Ward assumes the presence of an enzyme which effects the delignification, but 'did not succeed in extracting the enzyme from his cultures.'

Biffen ('01) has published some investigations upon the biology of Bulgaria polymorpha and the effects of its action on wood. Sections from a block of Oak thoroughly permeated by hyphae showed a swelling of the

[Annals of Botany, Vol. XVIII. No. LXIX, January, 1904.] 
thickening layers of the woody elements, which, on treatment with colour stains, gave indications of the presence of cellulose, suggesting that the action of the Fungus was one of delignification. Biffen also observed a sharply defined zone of cellulose surrounding many of the pits, especially in the vessels. He considers that the action of Bulgaria polymorpha upon Oak-wood causes the dissolution and probably decomposition of the lignin, and has assumed the existence of a delignifying enzyme to explain these results.

Czapek ('99) claims to have isolated a delignifying enzyme from Merulius lacrymans and Pleurotus pulmonarius. From the fungus-extract, by precipitation with alcohol, he obtained a white precipitate, soluble in water, which destroyed the lignin of the woody cell-walls. This fungusextract, he states, lost its wood-destroying properties when once boiled.

Hermann von Schrenk ('00) has described a disease of the Red Cedar caused by Polyporus Funiperinus, which attacks the walls of the wood-fibres, and extracting the lignin substances leaves a basis of almost pure cellulose. The amount of wood-fibre reduced to cellulose is very considerable, and it is supposed that some very potent lignin-splitting enzyme is concerned in the changes which are brought about. Schrenk ('03) also described a delignification in the wood of Fraximus due to Polyporus fraxinophilus, which is said to give off an enzyme which attacks the inner parts of the wood-cells, extracting the lignin, and leaving an impure cellulose.

Some evidence may be gathered with reference to cellulose occurring normally in the xylem.

Writing in 1860 Sanio ('60) states that the tertiary thickening gelatinous layer of lignified cells was first pointed out by T. Hartig and confirmed by von Mohl, and finally claimed by Schacht as an element present in all woody cells, which never becomes lignified but consists always of pure cellulose. Sanio regards this latter statement as too sweeping, and maintains that the share which this tertiary layer takes in the thickening of the woody cells varies greatly, sometimes being very strongly pronounced, at other times hardly perceptible. He mentions Acer platanoides as a stem in which this layer, which is coloured violet with chlor-zinc-iodine, is most distinctly to be observed; and adds a list of seventeen species in which this cellulose thickening is found in the wood-fibres.

In his general considerations on the structure of the Oak (p. 94), Hartig, speaking of the wood-fibres, says that in the walls of these fibres two, often three, layers can be distinguished, differing in their chemical behaviour. The most external, always a very thin layer, which is united with the corresponding layer of adjacent organs, encloses a very thick inner layer. This is lignified, and only in isolated cases is bounded internally by a third layer, which colours blue with chlor-zinc-iodine. Hartig himself makes only slight further allusion to this occurrence, as when discussing Hydmum 
diversidens, he mentions the most internal, somewhat gelatinous layer of many healthy Oak wood-fibres, which colours blue with chlor-zinc-iodine. He evidently regarded the character as so limited as to be negligible, and the fact as noted by him appears to have escaped attention.

Strasburger ('91) in the 'Leitungsbahnen' mentions incidentally that the inner thickened layer of the wood-fibres of Robinia psendacacia colours violet by potassium iodide; and also that in Wistaria the wood-fibres show an inner thickened layer, sometimes almost completely closing the lumen, which on treatment with potassium iodide and with chlor-zinc-iodine gave a beautiful wine-red colour.

In the case of Pimus sylvestris it has been shown by Schellenberg ('96) that the primary medullary rays remain unlignified until the third year ${ }^{1}$. He has also observed that among the wood-fibres generally the middle lamella is very often more lignified than the other layers, but that completely unlignified inner lamellae are only seldom met with, as in Triosetum perfoliatum.

With these exceptions I can find no reference ${ }^{2}$ to the presence of cellulose in mature wood, except as the result of the destructive action of certain Fungi. Abromeit ('84) mentions that after the use of chlor-zinciodine he has been unable to detect the tertiary gelatinous layer in the wood-fibres of the Oak, and, so far as I have been able to trace, it has come to be very generally accepted that the elements of the wood become entirely lignified, using the term in its simplest acceptation.

After an extended examination of a very large series of specimens I have detected the presence of cellulose in the xylem of many trees as a normal condition in perfectly healthy and vigorously growing stems. It occurs chiefly in the wood-fibres, and proves to be by no means an exceptional occurrence.

$\mathrm{My}$ attention was first drawn to this question when studying the action of a Bacterium (Pseudomonas destructans) ('99) upon the cell-walls of storage tissues, such as in Turnip, Carrot, \&c., and following up some investigation into the destructive action of this parasite upon the xylem. Small pieces of the xylem of Quercus and Fagus were sterilized by steaming in test-tubes in which they were half immersed in water, and afterwards were sown with a pure culture of this Bacterium. After an interval of fourteen days transverse sections showed a very marked presence of cellulose, as indicated by chlor-zinc-iodine and haematoxylin. As this seemed to suggest an action by the Bacterium corresponding to that of the Fungi above mentioned, it became necessary to determine whether this cellulose was present before inoculation.

1 I have observed cells in the medullary rays remaining unlignified for a much longer period.

${ }^{2}$ De Bary (Comp. Anat., Engl. ed., p. 482), quoting Sanio, mentions the occurrence of this gelatinous layer, which remains unlignified. 
On examination of pieces of wood from the same branch, before sterilization, I was surprised to find that in many sections a thick layer was present in several of the fibres which gave the violet colour characteristic of cellulose, when treated with haematoxylin; and similar sections showed a layer in the fibres which refused to react to phloroglucin. Treatment with iodine and sulphuric acid also gave the characteristic blue. This unlooked-for result in apparently sound wood led me to examine a number of shoots of Oak of various ages, carefully selected for their vigorous growth and entire freedom from disease.

For the purpose of this investigation it was specially important that fresh material only should be used. Pieces of felled wood left in the open, even for a short time, would be liable to the objection that any cellulose present in the xylem might be due to the process of decay. For this reason freshly cut branches were always used and the sections made generally, on the day following that on which the material was obtained, when it was still fresh and before any change could have taken place. Shoots of Oak were selected from trees growing near sheltered river banks and from those fully exposed in the open country. At first transverse sections were cut by a microtome through stems of varying ages and about $1.3 \mathrm{~cm}$. in diameter. The sections thus obtained were stained with phloroglucin and anilin sulphate, and it was found that in certain areas the internal layer of the walls of the fibres refused to act to these stains and remained as a white layer inside the otherwise coloured layer, but when treated with Schultze's solution, with iodine and sulphuric acid, or with haematoxylin, the characteristic blue colour was at once given by this layer. These tests are all confirmatory one of another, and leave no doubt that the substance of the inner layer was of the nature of cellulose. As haematoxylin alone sufficiently indicated these results permanent preparations were made by using Delafield's haematoxylin and mounting in Canada balsam.

In transverse section this cellulose layer appeared as a broad violet lining, gradually shading off towards the middle lamella, sometimes being partially detached and lying kinked in the lumen (see P1. VIII, Fig. 2). Longitudinal sections confirmed the above observations, the cellulose lining being sometimes torn out by the razor and resembling an isolated prosenchymatous element. It was noticeable in longitudinal sections that around the bordered pits a layer of violet was often present when stained with haematoxylin or Schultze's solution, showing that the bordered pits were also surrounded by a ring of cellulose.

The fibres containing the cellulose lining occurred singly, in isolated groups, or in broad bands concentric with the annual rings and interrupted by the medullary rays; but they seldom passed round the whole of the stem. It was necessary to cut across the entire stem, for, although the 
wood fibres in certain small sections might give no cellulose reaction, on taking complete transverse sections I never failed to detect this reaction in some area or another.

When stems of a larger diameter were employed it became necessary to divide them into smaller areas, and for this purpose they were cut into blocks about $1.3 \mathrm{~cm}$. square. These blocks were numbered, and by this means a transverse section of a large stem was obtained. In one instance the base of a young branch approximately sixteen years old, measuring 5.4 by $3.8 \mathrm{~cm}$., was divided by a fine saw into twelve blocks; sections were cut from each of the blocks, stained with Delafield's haematoxylin and mounted in Canada balsam. Although not one of these block-sections could be found which did not contain some fibres with a broad violet inner lining, in some they were quite isolated, while in others (more especially on the lower side) they presented a very conspicuous feature, so much so that their presence could be distinctly discerned by the unaided eye.

In another instance I specially felled a young Oak, approximately forty years old, the stem measuring $14 \mathrm{~cm}$. by $12 \mathrm{~cm}$. This was divided by a fine saw into eighty-eight blocks, all of which were numbered in order, and transverse sections were cut from each, stained in haematoxylin and mounted in Canada balsam. In this way a complete transverse section of this trunk was obtained. As in the case of the smaller branch some fibres with a violet lining could be detected in almost every one of the eighty-eight sections, but in certain portions of the stem they occurred in very conspicuous groups. These fibres were well marked in the blocks situated in the centre of the stem, that is around the pith, and containing the first few years of growth, which showed that the oldest wood was not completely lignified and contained a large proportion of cellulose. Its presence in the wood of the first years of growth was also noticed in many smaller stems. The cellulose was somewhat irregularly distributed, though it was evidently developed more markedly on one side of the tree than the other, and it is probable that the orientation has some influence in this direction (Fig. I).

The trees above-mentioned were growing in the neighbourhood of Newcastle-upon-Tyne. It became an interesting question to determine whether climatic conditions had any influence upon the composition of the xylem, and specimens of Oak were obtained from other parts of England, i. e. from Warwickshire, Yorkshire, and Surrey. Transverse sections from Oaks growing in all these localities presented the same appearance, when stained with haematoxylin, as has been already described. Fig. 2 represents a section of an Oak from Wimbledon, taken from a branch eight years old, diameter $1.3 \mathrm{~cm}$., showing strikingly the inner cellulose layer of the fibre-walls. The cellulose extended about one-third round the stem. From Warwickshire I was fortunate in obtaining, 
ten days after being felled, the base of a well-grown sound Oak, approximately sixty years old, and in this specimen too a considerable quantity of cellulose was found in the first years of its growth, and also distributed throughout the duramen and alburnum.

Branches of various other trees were next examined. In the wood of Fagus the occurrence of cellulose was equally as strongly pronounced (Fig. 3) as in Quercus, if not more so, in trees grown both in the north and central parts of England. It occurs chiefly in the broader annual rings which exhibit special development during a season of vigorous growth. As in the case of Quercus, the cellulose may be found at the very centre of the stem, and branches of twenty-five and thirty years both showed this peculiarity in the wood of the first and second years of their growth.

In Aesculus the cellulose, as indicated by the reaction to haematoxylin, was not so immediately apparent, and in specimens I first examined it was found only in the very young wood, and then quite locally. A further study, however, of numerous transverse sections of different trees showed it to be fairly prevalent in the growth of other years. The softer wood of Aesculus is very different in character to that of the trees considered above, and the inner lining of the wood-fibres is represented by a much thinner layer than is the case in many of the harder woods. In certain parts of the sections a thin lining can be observed inside the fibre-walls, which is stained violet with haematoxylin, and this is the most characteristic appearance; but in other regions, quite locally, the violet-blue layer may assume a thicker, more gelatinous appearance, and lie quite detached and often crumpled in the lumen. This thicker layer sometimes occupies a large part of the fibre-lumen, and shades into a paler colour towards the middle lamella, being edged inside with a darker line. In one instance I found this disposition of the cellulose along a radius extending throughout the third to the ninth years, though most noticeably present in the third and sixth years, which showed a more vigorous development, while in other parts of the annual rings it was entirely absent. In another section it was well marked in the spring wood of the current year. The cellulose is more generally to be found in the spring than in the autumn wood.

In Salix the presence of the cellulose lining to the wood-fibres is often very pronounced. In one branch, with a diameter of $1.6 \mathrm{~cm}$. and containing ten annual rings, cut from a willow growing at the edge of a large pond, hardly a single fibre could be detected which did not show a broad violet inner layer when treated with chlor-zinc-iodine. Sometimes this layer completely closed the lumen of the fibre. In another instance, in a branch with a diameter of $3.7 \mathrm{~cm}$, with twelve annual rings, from a tree growing upon a hillside with northern aspect, in many of the fibres no violet colour due to chlor-zinc-iodine could be observed, and also where the edge of the lumen was coloured deep violet this colour gradually 
shaded away toward the middle lamella. The difference in the manner in which the fibre-walls reacted to chlor-zinc-iodine was most marked in the two cases, and this may perhaps be attributed to the different situations.

In longitudinal sections these appearances are well-marked, the cellulose lining of the fibres being easily recognized. The cellulose ring round the pits on the walls of the vessels was exceedingly striking when stained in chlor-zinc-iodine. Fig. 4 is taken from the branch of the tree growing at the water-side. The iodine and sulphuric acid ( 76 per cent.) reaction agreed with the results obtained from chlor-zinc-iodine. In longitudinal sections, especially, it was most beautiful to see the edges of the pits turn blue in turn as the acid gradually swept over them. Further confirmation was obtained by treatment with Congo-red and also with haematoxylin.

In the wood of Ulmus each annual ring commences with large woodvessels succeeded by wood-parenchyma and fibres. When stained with haematoxylin and mounted in Canada balsam the wood-fibres are especially conspicuous by their thick yellow walls, inside which, in many instances, a distinct blue-violet lining of cellulose may be detected.

An Almus stem obtained from the banks of a stream in Warwickshire, about ten years old, and having a diameter of $2 \mathrm{~cm}$., showed the presence of cellulose very distinctly round one half of the stem, while in the other half it was entirely absent. The development occurred chiefly in the third, fourth, fifth, and sixth years, being especially prevalent in the very wide fourth year, as indicated by the inner thickened layers staining clearly blue-violet with haematoxylin.

A branch of Betula six years old, with a diameter of $1.4 \mathrm{~cm}$., was also examined. This, upon treatment with haematoxylin, indicated a special prevalence of the swollen cellulose layers in the fourth and fifth years.

In Fraxinus, unlike the other woods examined, no well-marked patches of wood-fibres, in which a broad lining of cellulose is present, could be seen. The specimen from which my sections were taken was a vigorous and healthy sapling, with a diameter of $2.7 \mathrm{~cm}$. and twelve annual rings. The stem had therefore grown quickly. It was obtained in July, and the next day sections were cut, stained with Delafield's haematoxylin, and mounted in Canada balsam. In none of the sections, however, could any characteristic development of the thickening gelatinous layer be found; at most on the internal surface of some of the fibres there might be detected a very thin line of blue, and this was found to be true of all the trees afterwards examined.

It had now become perfectly plain that a thickening layer of cellulose occurred quite commonly as a natural feature in the woody fibres of 
a variety of trees in all situations, probably representing a stage of arrested development. As this fact has not hitherto been recognized the observation is important, and has some bearing upon the study of fungoid action in timber.

It is well known that boiling water has a destroying and dissolving action upon the cell-wall. As long ago as 1882 Singer ('82) has shown that four substances can be extracted from xylem by boiling water, namely, vanilin; a substance which shows the reactions of coniferin; a gum, which is soluble in water; and a substance soluble in water not identical with the other three; these all entering into the composition of what is known as lignin, though in what relationship is not determined.

Recently, Van Wisselingh ('98) has shown that by heating sections of the root of Beta vulgaris for six hours in distilled water, at a temperature of about $125^{\circ} \mathrm{C}$., a pure cellulose wall remains behind, and the pectin substances are destroyed and removed. It seems probable that the operation of sterilizing by discontinuous boiling would have some such effect upon the lignified walls, and that some substances might be destroyed or removed from the cellulose matrix during the process; in other words it would have a delignifying action.

The wood of Fraximus affords very suitable material for studying the action of boiling water upon the xylem; since, as far as I have been able to determine from the examination of numerous sections taken from various trees, no broad inner lining of cellulose is present in the fibres. The xylem appears to undergo complete lignification. Transverse sections were taken from a stem ten years old and about $2.4 \mathrm{~cm}$. in diameter, and some of these were examined at once with chlor-zinc-iodine. Fig. 5 is a good illustration of the appearance presented, the walls are thick and hard and show no trace of violet colour, the only effect of the chlor-zinc-iodine being to turn the walls yellow. The other sections were placed in a boiling tube half filled with water and steamed for about two hours on consecutive days, remaining immersed in water the whole time. Some of these sections were removed at intervals and subjected to treatment with chlor-zinc-iodine. After two days some delignification was slightly indicated; after three days it was well pronounced. Fig. 6 represents the general appearance after four days: the middle lamella is a bright yellow, while the inner layers of the fibre-walls are swollen and stained violet, more deeply on the inner surface and shading away towards the middle lamella, showing almost complete delignification. A comparison of the sections before and after boiling represented in Fig. 5 and Fig. 6 shows in a most marked manner the delignifying action of the boiling water. It should be noted that in the sections steamed four times a delignification had already commenced in some of the wood-vessels. 
The xylem of Fraximus is somewhat resistent to the action of boiling water, the same effect being produced in other woods after a less severe treatment; but it has been selected for illustration because of the certainty of obtaining sections not exhibiting incomplete lignification in any part before boiling.

In the case of Aesculus the delignifying action of boiling water is well marked. A portion of a healthy stem of Aesculus was procured, with a diameter of $2.2 \mathrm{~cm}$. and ten annual rings. Sections containing the whole surface were cut by means of a microtome and placed in a boiling tube half-filled with distilled water and steamed for two hours on three consecutive days. The sections were then treated with chlorzinc-iodine and phloroglucin, and permanent preparations made by staining with Delafield's haematoxylin and Congo-red (Fig. 7) and mounting in Canada balsam. (Similar preparations to serve as controls were made before steaming.) When stained with chlor-zinc-iodine the appearance was most striking and in strong contrast to the unboiled sections. Instead of only in certain areas, the fibres and wood-cells in nearly every part contained a swollen blue-violet-coloured layer, which was frequently broken away and lying in contorted shapes in the lumen (see Fig. 7), while the middle lamella remained yellow; the walls of the vessels were yellow, swollen, and striated, but lined with a faint blue tinge. The action of phloroglucin fully confirmed that of chlor-zinc-iodine. The middle lamella of the fibres showed the characteristic red, while the inner layers were quite white and colourless; the walls of the vessels also stained red, but they were swollen, and a white unstained lining might in some cases be detected. The annual rings stood out distinctly red with phloroglucin, but when stained with chlor-zinc-iodine the elements composing these rings showed the inner layers swollen, striated, and yellow, enclosing a blue lining. Prolonged steaming further emphasized these results.

Sections subjected to discontinuous steaming for six days when stained with chlor-zinc-iodine showed the inner layer of the fibres a deep blueviolet, much swollen and in many cases obliterating the lumen; the walls of the vessels and tracheides were much swollen and showed distinctly violet; the elements forming the boundary of the annual rings too had a well-marked violet lining. With phloroglucin the walls of the fibres remained white, and in some cases even the middle lamella refused to stain; in the vessels too there was a distinct inner white layer, the medullary rays staining red.

Among the many stains for lignin, Hegler ('00) has shown that thallin sulphate stains the vanilin yellow and phenol the coniferin a blue-green. The action of these stains on steamed wood is of importance, and gives confirmation of the results already obtained with phloroglucin. Steamed transverse sections from the same piece of Aesculus treated with thallin 
sulphate showed the middle lamella of the wood-fibres a distinct yellow, but enclosing an inner layer remaining white and unstained. The walls of the wood-vessels and tracheides stained yellow. In the longitudinal sections the same peculiarities of staining were noted, but in the woodvessels the borders of the pits remained unstained. Similar sections when stained with phenol showed the middle lamella of the wood-fibres green, but the inner layers of the walls white and unstained; the wood-vessels and tracheides stained green. Again, in longitudinal section the borders of the pits were unstained. Phloroglucin stained precisely the same structures, and again the borders of the pits remained unstained.

Similar investigations with Quercus, Alnus, and Ulmus gave the same results. Fig. 8, showing a transverse section of Quercus after steaming, depicts a stage in which the progressive action of the delignification may be observed. The violet colour given by chlor-zinc-iodine is seen staining deeply around the lumen, and suffusing itself gradually outwards into the lignified layers.

The above experiments show that boiling water extracts some substance of the nature of lignin from the wood of all these trees and that sterilization by steaming would have a similar effect. To determine this point further some sawdust was obtained from a piece of Aesculus (diameter $3.5 \mathrm{~cm}$., annual rings 19), covered with distilled water, and steamed for half an hour on one afternoon and again for an equal time next morning. The sawdust was then removed by filtration through an ordinary filter paper. A small portion of the watery extract thus obtained reacted very feebly to phloroglucin, but the colour was sufficient to indicate that some substance was present which gave the lignin reactions. The remainder of the filtrate was next extracted with ether, the water drawn off with a separating funnel, and the ether evaporated in a small white crucible on a water bath at $60^{\circ} \mathrm{C}$. A brown deposit remained as a thin layer in the crucible after the ether had disappeared. This brown layer gave at once the characteristic red colour when a drop of phloroglucin was added.

In order to avoid any risk of minute fragments of wood passing through the filter paper and hence into the ether, or by any chance some substance being extracted from the filter paper which might react to phloroglucin, a similar watery extract of Aesculus sawdust was passed through a Kitasato tube, extracted with ether, and the ether evaporated. The result on addition of a drop of phloroglucin to the residue was the same, the red colour was instantly given. It only remains to say that the ether and distilled water alone, after the same treatment, gave no brown deposit, and not the slightest reaction to phloroglucin.

This shows conclusively that a substance which reacts to phloroglucin is extracted from Aesculus wood by boiling water, and confirms in a remarkable manner the reactions to the lignin and cellulose tests of the 
boiled sections of this wood. In fact, the process of sterilization by steaming delignifies the xylem and produces appearances exactly similar to those described after the action of Fungi.

As a confirmation of these results with Aesculus it seemed worth while to try other woods, and pieces of Elm, Ash, Oak, and Scotch Pine were tested. From each of these, after removal of the bark, sawdust was obtained and placed in small flasks containing water. These were then steamed on three days for two hours, the decoctions filtered, extracted with ether and the ether evaporated. In all these cases a brown deposit was left after the evaporation of the ether which at once gave the characteristic red colour with phloroglucin.

The above experiments having so clearly shown the effect of boiling water in extracting from xylem a substance which reacts to phloroglucin and thallin sulphate, it seemed probable that cold water would have the same power if allowed to act for a longer period. From the stem of the forty years' Oak already mentioned small chips of alburnum and duramen were carefully made and five gram. of each placed in flasks containing I 50 c.c. of distilled water and 5 c.c. of chloroform. The flasks so prepared will be referred to as the 'extract' of alburnum and duramen respectively. In all eight of these flasks were prepared, four containing alburnum and four duramen, which were then placed in an incubator at $28^{\circ} \mathrm{C}$. After three days one flask of alburnum-extract was taken, the water filtered and extracted with ether, and the ether then divided into three portions in three porcelain crucibles; it was then evaporated at $60^{\circ} \mathrm{C}$. A thin brown layer was deposited inside these crucibles which reacted at once, in one case to phloroglucin and in another to thallin sulphate (both of these being tests for vanilin), while the third gave no result with phenol, the test for coniferin. A flask of duramenextract was similarly treated and gave precisely the same reactions.

These results show that a substance answering to the vanilin tests is dissolved out in cold water. Thus cold water has also an extractive power, and by continued soaking in water the xylem undergoes a partial delignification.

The effects of boiling and immersion in water here described were under the exaggerated conditions produced by the use of thin sections and fragments of wood, yet it must be allowed that some delignifying action would take place upon even small blocks of wood subjected to steaming in water for the purpose of sterilization and remaining under damp conditions for many months during cultural experiment.

It will be noted that the coniferin, or rather a substance answering to the test for coniferin, was apparently not extracted from the xylem. This result appears curious and somewhat at variance with the fact that the steamed sections, when treated with phenol- $\mathrm{HCl}$, always gave an un- 
coloured inner layer, which seemed to indicate that the 'coniferin' had been removed. Some explanation, however, was gained by a comparison with fresh sections treated in the same manner. These showed a very limited distribution of the 'coniferin,' it being found chiefly in the vessels, tracheides, and elements surrounding them, and appearing to be absent in a great measure from the fibre-walls. This suggests an interesting point touching upon the distribution of the vanilin and coniferin in woody stems, which remains to be followed up; and it appears to furnish a clue to a problem which presents itself. Would not the water passing up the stem as the transpiring current have a tendency to dissolve the 'lignin'? The walls of the vessels and other elements connected with the transmission of water are apparently impregnated with some substance not readily soluble in water.

To return to the alburnum and duramen 'extracts.' Of the eight flasks six remained in the incubator. After eight days another pair of these flasks was similarly treated and the ether extracted, divided into three porcelain crucibles, and evaporated as before. To my surprise the residue, after evaporation of the ether, gave only a faint reaction to phloroglucin and thallin sulphate in the case of the duramen, and the reaction with these stains was even less for the alburnum. This result at first seemed inexplicable, but I noticed that the extract in the flasks, especially that of the alburnum had become somewhat turbid. This seemed to indicate the presence of Bacteria, although it should be remarked that some of the chloroform still remained at the bottom of the flasks so that the water in which the Oak chips were immersed would be saturated with chloroform. However, as I have shown in a previous paper ('00), no reliance can be placed upon chloroform, thymol, \&c. as antiseptics, as these substances do not necessarily prevent the growth of micro-organisms eve when used in considerable strength.

To ascertain whether any micro-organisms were present stab-cultures from these flasks were made in sterile, plugged test-tubes containing beef-, Liebig-, and turnip-gelatine. These test-tubes were then incubated for five days, at the end of which time colonies of Bacteria were found in all the tubes. It may be mentioned here that stab-cultures subsequently taken from the remaining two pairs of flasks, after fourteen days and after thirty-two days, also developed colonies of Bacteria. The extracts from the flasks after these intervals gave much the same colour reactions as before, distinct though faint for the duramen and hardly perceptible in the case of the alburnum.

No attempt has been made at present to isolate and identify these Bacteria, but it may be remarked that the Bacteria from the alburnum invariably liquefied the gelatine, while in the tubes sown from the duramen the gelatine remained unliquefied. 
The inoculation of the gelatine tubes from the cold-water extract of the Oak duramen and alburnum and the subsequent development of colonies clearly showed that Bacteria were present in these solutions, but further proof was needed to show whether or no these Bacteria could live upon and destroy the substance extracted from the wood by water. To determine this point strong decoctions were made from splinters of the duramen and alburnum of the same forty years' old stem. The splinters were boiled in water in two flasks, and after standing all night in the steamer were again boiled on the following morning. The decoctions thus obtained were freed by filtration from any particles of wood and drawn into smaller flasks, each containing 150 c.c. of decoction. In this manner eight flasks were prepared, four containing each I50 c.c. of alburnum decoction and four containing each I 50 c.c. of duramen decoction. These will be referred to as alburnum- and duramen-'decoctions.' These eight flasks were then plugged with cotton wool and sterilized by discontinuous steaming. Of the eight flasks one of each kind was used for a control.

Of the other three flasks of alburnum-decoction one was sown with Penicillium, another with Bacillus subtilis - a pure culture obtained from Dr. Kral-and the third from the alburnum-extract in which the Bacteria had developed. Similarly one flask of duramen-decoction was sown with Penicillium, a second with $B$. subtilis, and the third from the duramenextract in which Bacteria had developed. These flasks together with the controls were incubated at $28^{\circ} \mathrm{C}$.

Flasks sown with $B$. subtilis. After twenty days stab-cultures were made on gelatine-tubes of Koch's beef-bouillon and Liebig-extract, and the flasks were then extracted with ether and tested as before. With phloroglucin the duramen-residue gave a most distinct red, but the colour was much fainter in the alburnum-residue. With thallin sulphate the colour was indicated in both cases but more faintly in the alburnumresidue, and with phenol- $\mathrm{HCl}$ no reaction could be detected in either case. In the stab-cultures, colonies developed from the alburnum-decoction, but not from the duramen. This experiment seems to indicate that $B$. subtilis can grow in the alburnum-decoction and destroy the substance extracted from the wood, while it is incapable of living in that obtained from the duramen.

Flasks sown from alburnum- and duramen-extracts. After twentyone days stab-cultures were made from both flasks in tubes of beef-bouillon and Liebig-extract. The stabs from the alburnum-decoction developed colonies which quickly liquefied the gelatine, but the colonies from the duramen-decoction developed much more slowly and without liquefying the gelatine. The ether-extracts from the alburnum-decoction showed no colour with either phloroglucin or thallin sulphate, but in the case of the 
duramen-decoction both phloroglucin and thallin sulphate gave the characteristic colours, but somewhat faintly. Phenol- $\mathrm{HCl}$ gave no colourreaction in either case.

Flasks sown with Penicillium. After twenty-three days several colonies had developed in the alburnum-decoction and produced conidia, but in the duramen-decoction no signs of colonies could be detected. With phloroglucin and thallin sulphate the ether-extracts gave very distinct reactions in the case of the duramen-decoction, but with the alburnum the colour was very much fainter. Phenol- $\mathrm{HCl}$ gave no colour-reaction in either case.

The control flasks were next examined (after twenty-five days). The ether-extracts from both the alburnum- and duramen-decoctions gave the characteristic colours most distinctly with both phloroglucin and thallin sulphate, but not with phenol- $\mathrm{HCl}$, again showing that the vanilin is extracted but not the coniferin.

This experiment was repeated with decoctions of the alburnum and duramen from the sixty years-old Warwickshire Oak, using 2 gram. of wood to each Ioo c.c. of water. The results were in all respects confirmatory of those just described.

These experiments show very clearly that the substance extracted from the Oak-wood by water, which reacts to phloroglucin and thallin sulphate, is destroyed by certain Bacteria and in some measure by Penicillium. Both $B$. subtilis and the Bacteria which developed naturally in the extract, grew vigorously in the alburnum-decoction and destroyed the substance extracted from the wood. Bacteria being thus able to destroy the 'lignin' substances, this fact explains why the colour-reaction to phloroglucin was no longer given in the cold-water extract after eight days (p. I 32 ).

It is further demonstrated that the alburnum is more readily acted upon by these organisms than the duramen. This is an important consideration, and suggests that the duramen contains substances not possessed by the alburnum which are unfavourable to the growth of Fungi or Bacteria.

These investigations throw some light upon the natural decay of timber, and suggest that one of the initial stages of decay is the extraction by water of some substance or substances from the xylem; by this process the cellulose is exposed, and it is then liable to be attacked by vegetable saprophytes. The fact that these organisms do not grow so readily in the watery-extract from heart-wood is suggested as a reason why the heartwood is more durable.

In criticizing Singer's work Czapek considers his conclusions to be erroneous. He, however, makes no mention of repeating his experiments; while my results support Singer and prove that he was right in attributing 
to boiling water the power of extracting certain substances from the xylem which give the so-called lignin reactions, and the extractive power would be greatly increased under Singer's conditions owing to the very long process of boiling to which his material was subjected. I have shown further that this delignification of the xylem may be accomplished by cold water. The relationship of the substance extracted by water to the hadromal which has been extracted by Czapek by means of a boiling solution of zinc chloride needs to be determined.

Czapek ('99) has isolated a delignifying enzyme, but the details given of his experiment are not very complete. He employed the mycelium of Pleurotus pulmonarius and Merulius lacrymans, obtained from wood decaying under the influence of these Fungi, presumably not pure cultures. From these a watery extract was obtained and to the filtrate a small quantity of wood-filings added, together with chloroform, and incubated at $28^{\circ} \mathrm{C}$. The alcoholic-extract, tested with phloroglucin, after three days showed no reaction; after eight days a positive but weak reaction; and after fourteen days the reaction was tolerably strong, while the wood was coloured strongly violet with chlor-zinc-iodine.

In considering these experiments it would be useful to know from what tree the wood-filings were made, and again whether the wood-filings were examined previous to being subjected to the Fungus-extract, in order to determine whether any cellulose was present. The subsequent blue colour given by chlor-zinc-iodine cannot be accepted as evidence that the wood-filings had been delignified by the action of the Fungusextract. Water alone extracts substances from wood which react to phloroglucin, and chloroform is not efficient in preventing the growth of Bacteria which would inevitably complicate the experiment. Positive evidence in favour of the hadromase is given by the fact that the Fungusextract lost its wood-destroying properties when boiled, and that a white precipitate was thrown down by alcohol which had the same destructive action upon lignified cell-walls. It does not, however, afford absolute proof that the hadromase is a product solely of the Fungus, as, unless pure cultures were used under the strictest precautions to exclude Bacteria, the problem is complicated by the probable development of these organisms, which I have shown also possess the power of destroying lignin compounds.

The important papers by Marshall Ward upon the biology of Stereum hirsutum, and by Biffen upon the biology of Bulgaria polymorpha, which treat of the action of these Fungi upon the xylem, afford strong evidence in favour of a delignifying enzyme, these authors describing a gradually progressive delignifying action of the Fungus.

In the examination of his cultures of Stereum hirsutum upon Aesculus wood, with the reagents for differentiating lignified membranes from those 
devoid of lignin, Marshall Ward finds 'during the first month no distinct reactions .... and stains, such as Delafield's haematoxylin, do not colour the walls blue or purple, but merely brown or yellowish; but in some cases a thin lining layer is found to react in wood acted on by the Fungus for six weeks to a couple of months, and the altered layer gets more and more decided as the action progresses.' The unequal distribution of cellulose make it possible that its presence might have been overlooked in the first blocks examined, and no mention of any examination of the blocks prior to sterilization is made. I have not had the opportunity of studying a quite freshly cut stem of Aesculus of more than about three inches in diameter, but, judging from numerous sections of small branches and some much larger pieces of Oak, the distribution of cellulose is always somewhat irregular, and hence certain of the blocks cut from a good-sized stem might be entirely lignified, while in others lignification would be by no means complete. In Aesculus this partial lignification occurs more especially in the spring wood, and this may explain why it was found that 'in some transverse sections the spring wood is invaded much more rapidly than the autumn wood of the same annual ring' when attacked by Stereum hirsutum. Marshall Ward's figure I7 corresponds exactly with many sections I have seen of normal wood not attacked by any Fungus.

In his description of tangential longitudinal sections of cultures a month old which had been treated with gentian-violet and Congo-red, Biffen noted that it was easy to find, especially in the vessels, walls in which every pit was marked out by a well-defined, bright pink zone surrounding it, indicating that that portion of the wall had been delignified and a cellulose basis staining with Congo-red remained. It is significant that he observed, moreover, "that no hyphae passed through the majority of these pits, so that one has to assume the secretion of a delignifying enzyme in quantity by the fungus into the wood-elements.' This appears to be an unnecessary assumption which cannot be allowed in face of the fact that this appearance is observed very commonly without any Fungus being present. That the margins of the bordered pits often remain unlignified, especially where the vesisel crosses the medullary rays, has been demonstrated in the instances above quoted; and that it is no mere optical illusion is shown from the fact of the borders of the pits staining distinctly blue upon treatment with iodine followed by sulphuric acid, as in Salix (compare Fig. 4). Among herbaceous stems also I have observed this ring of cellulose very beautifully shown by chlor-zinc-iodine in the large wood-vessels of Cucurbita.

It has become clear that the presence of cellulose in the wood-fibres cannot be attributed entirely to the action of a delignifying enzyme, and it is now necessary that the enzyme in each case should be isolated. 
Granted that the Fungus finds in the cellulose a necessary food-element and given the existence of layers of this substance in the wood-fibres, it follows that the hyphae would proceed in the direction of the source of supply, and the delignifying enzyme only comes into play where this supply is no longer available. The large amount of cellulose which is now shown to occur in the wood, at all stages, having been previously unrecognized, the conclusion becomes inevitable that much of the effect ascribed to the action of Fungus-hyphae is referable to conditions already present, and the action upon the xylem due to any process of sterilization must be taken into account when estimating the effect of the penetration of hyphae into the wood in culture experiments.

Without denying the existence of a delignifying enzyme, it is probable that the Fungus first attacks the elements where cellulose is already present, which would account for the direction in which the destruction of the wood sometimes advances. Thus in the formation of partridgewood by Telephora perdix the Fungus attacks certain areas which eventually become hollow. Possibly these areas are those in which cellulose is present and which, therefore, succumb first, and the hyphae penetrate along the line where it is to be found, and the same reason may explain why Polyporus sulphureus extends in the direction of the annual rings.

In describing the process of decay in the Oak, due to Polyporus dryadeus, Fr., Telephora perdix, M., and Stereum hirsutum, Fr., Hartig distinguishes two methods of attack, one accompanied by delignification and another in which the conversion of lignin into cellulose does not take place. It is conceivable that Hartig may be describing the action of these Fungi upon elements already containing cellulose and upon those in which cellulose is absent. The fact that in the former method of attack the progress of decay is more rapid gives support to this suggestion.

It appears probable that the occurrence of cellulose in certain areas represents a stage of arrested development. The largest distribution of cellulose was very frequently observed in the wider annual rings, in which the wood appeared to have grown rapidly in a favourable season, and the direction of orientation evidently has its influence also. There may be some connexion with the phenomenon known to gardeners as the 'ripening' of the wood, and in certain seasons when the wood is said not to 'ripen' it may be an expression of the fact of an incomplete lignification. I may mention that I imagine this condition of partial lignification may be found to be generally prevalent. Among herbaceous plants, for instance in Vicia faba and Oenothera biennis, in the older stem-internodes just above the surface of the ground the cellulose lining of the wood-fibres is very beautifully shown. 


\section{SUMMARY.}

I. It is found that a gelatinous thickening layer which reacts at once to the various colour-tests for cellulose occurs very commonly, though very irregularly, in the fibre-walls of the xylem as a normal condition in a great number of perfectly healthy trees, in all localities and situations. It may have a very partial distribution, or may occur very generally and conspicuously through the stem, and may be present only in parts of the same annual ring. Sometimes this innermost layer is represented only by a thin lining, at other times by a very broad band which appears swollen and occupies a large part of the lumen.

A margin of cellulose is also often present round the bordered pits.

2. A delignification of the xylem is effected by the action of boiling water, which removes substances which impregnate the cellulose and react to the lignin stains, leaving a basis of cellulose as indicated by the reactions to the various colour-tests. This is shown by submitting thin sections of wood to the action of boiling water, and is confirmed by the fact that ether removes from the watery extract obtained from sawdust and fragments of wood a substance which reacts to lignin tests.

Further, cold water, operating for a longer period, has a similar power in extracting from the xylem a substance which reacts to phloroglucin and thallin sulphate, and thus by continued soaking in water wood undergoes a partial delignification.

A substance showing a blue-green colour with phenol- $\mathrm{HCl}$, the test for coniferin, is apparently not extracted.

3. It is demonstrated that the 'lignin' substances extracted from the xylem by water are destroyed by certain micro-organisms, and that these flourish more vigorously in the sap-wood than in the heart-wood extracts. This latter point suggests that the heart-wood contains some substances not readily attacked by Fungi or Bacteria, and accounts for the fact of its greater durability.

4. The presence of this unlignified layer in the wood-fibres probably represents a stage of arrested development. Its general prevalence having been overlooked, the conclusion is inevitable that the occurrence of cellulose which has been attributed to the action of Fungi must to some extent be ascribed to conditions already present, and the effect of any method of sterilization must also be taken into account. The delignification cannot be entirely attributed to an enzyme secreted by Fungi.

\section{POSTSCRIPT.}

Since the above was written I have examined the roots of Lupinus, Phaseolus, Polygala Senega and Aesculus, and have found the cellulose lining in the fibres very distinctly shown in all these cases. Doubtless fibres remaining partially unlignified are of quite common occurrence in roots. 
In view of the examination of additional specimens of Fraximus grown in a different situation, my statement with regard to the complete lignification of the fibres requires some modification. Recently I have had the opportunity of examining the wood of Fraximus attacked by Polyporus hirsutus, and found that when the xylem was treated with chlor-zinc-iodine the fibre-walls became an intense blue. In accordance with the observations previously made, this seemed to indicate a delignification due to this parasite. But on examining perfectly healthy shoots from the same tree, and also others from trees in the same locality quite free from any fungoid attack, it was at once seen that in these cases many of the fibres were only partially lignified; hence the delignification was not primarily due to the action of this Polyporus. Local conditions of soil and climate seem in some cases to retard the complete development of the xylem, and thus render such trees constitutionally weak and very liable to attack. For instance, in the particular locality now under consideration very few of the trees were free from the infection of Polyporus hirsutus.

\section{LITERATURE.}

Aвromeit, J. ('84) : Ueber die Anatomie des Eichenholzes. Prings. Jahrbücher für wissensch. Botanik, Bd. $x v, 1884$.

Brffen, R. H. ('01): On the Biology of Bulgaria polymorpha, Wett., Annals of Botany, vol. xv, I 901 .

Czapex, F. ('99): Ueber die sogenannten Ligninreactionen des Holzes. Zeitschr. für physiol. Chemie, Bd. xxvii, S. I4I, I 899 ; Botanisches Centralblatt, Bd. lxxix, I899.

('99): Zur Biologie der holzbewohnenden Pilze. Berichte der deutschen Botanischen Gesellschaft, Bd. xvii, I899.

HARTig, R. ('78) : Die Zersetzungserscheinungen des Holzes der Nadelholzbäume und der Eiche. Berlin, 1878.

Hegler, R. ('00): Histochemische Untersuchungen verholzter Membranen. Flora, Bd. lxxiii, I890.

Marshall Ward ('97): On the Biology of Stereum hirsutum Fr. Philosophical Transactions of the Royal Society, vol. 189, I897, Series B.

Mayr, H. ('84): Zwei Parasiten der Birke, Polyporus betulinus, Bull. und Polyporus laevigatus, Fries. Botanisches Centralblatt, Bd. xix, I 884 .

Potter, M. C. ('00): On a Bacterial Disease of the Turnip (Brassica napus). Proc. of the Royal Society, vol. lxvii, 1900.

Sanio, C. ('60): Einige Bemerkungen über den Bau des Holzes. Botanische Zeitung, Bd. xviii, I86o. ('63): Vergleichende Untersuchungen über die Elementarorgane des Holzkörpers. Botanische Zeitung, Bd. xxi, I863.

Schellenberg, H. C. ('96): Beiträge zur Kenntniss der verholzten Zellmembran. Pringsh.Jahrbücher für wissenschaftliche Botanik, $\mathrm{Bd}$. xxix, I896.

Schrenk, H. von ('00): Two Diseases of the Red Cedar, caused by Polyporus juniperinus, N. Sp., and Polyporus carneus, Nees. U.S. Department of Agriculture, Bulletin No. 2 I, Washington, I 900 .

('03): A Disease of the White Ash, caused by Polyporus fraxinophilus. U. S. Department of Agriculture, Bulletin No. 32, Washington, 1903.

Singer, MAX ('82): Beiträge zur näheren Kenntniss der Holzsubstanz und der verholzten Gewebe. Sitzungsber. d. Wiener Akad., Bd. lxxxv, Abt. I ; Botanisches Centralblatt, Bd. x, I882.

Strasburger, E. ('91): Ueber den Bau und die Verrichtungen der Leitungsbahnen in den Pflanzen. Jena, I 89 I.

Wisselingh, C. van ('98): Microchemische Untersuchungen über die Zellwände der Fungi. Pringsh. Jahrbücher für wissenschaftliche Botanik, Bd. xxxi, I898. 


\section{EXPLANATION OF FIGURES IN PLATE VIII.}

Illustrating Professor Potter's Paper on the Occurrence of Cellulose in Xylem.

Fig. I. Transverse section of a young stem of Quercus, diameter $\mathbf{I} \cdot 3 \mathrm{~cm}$. The shading extending partially round the stem indicates the regions of cellulose distribution.

Fig. 2. Transverse section of wood-fibres from a stem of Quercus, cut when fresh and stained with Delafield's haematoxylin. The lignified layers are yellow and the enclosed gelatinous thickening layer violet. Zeiss D., Oc. 4 .

Fig. 3. Portion of a transverse section from the stem of Fagus, cut when fresh, showing the inner gelatinous layer present in some wood-fibres, coloured violet. Zeiss D., Oc. 4 .

Fig. 4. Longitudinal section from the wood of Salix, cut when fresh and stained with chlor-zinciodine. Showing the margins of the bordered pits stained blue.

Fig. 5. Transverse section of wood-fibres from the stem of Fraxinus, cut when fresh and stained with chlor-zinc-iodine. The yellow walls show a complete lignification with no internal cellulose layer.

Fig. 6. Similar section from the same stem of Fraximus, after boiling on four consecutive days and staining with chlor-zinc-iodine. The lignified parts of the walls remain yellow, while the inner swollen layers are coloured violet, having undergone delignification.

Fig. 7. Transverse section from a stem of Aesculus, steamed for two hours on three consecutive days, stained with Congo-red, and mounted in Canada balsam. The inner delignified layer of the fibre-walls is stained red and lies detached, swollen, and crumpled in the lumen.

Fig. 8. Transverse section of the wood-fibres from a stem of Quercus after steaming three times, stained with chlor-zinc-iodine. Showing the advancing process of delignification due to the action of boiling water. 

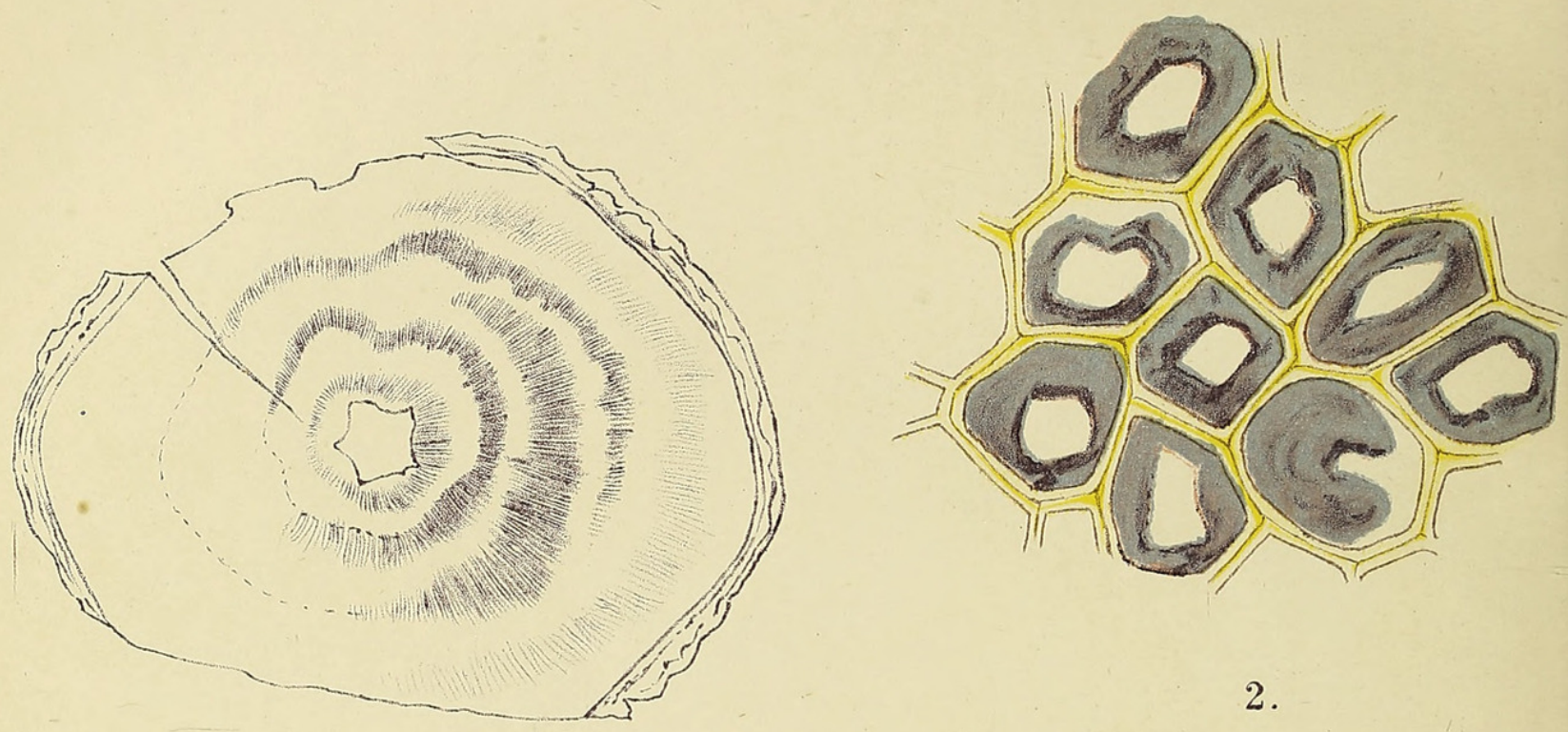

1.
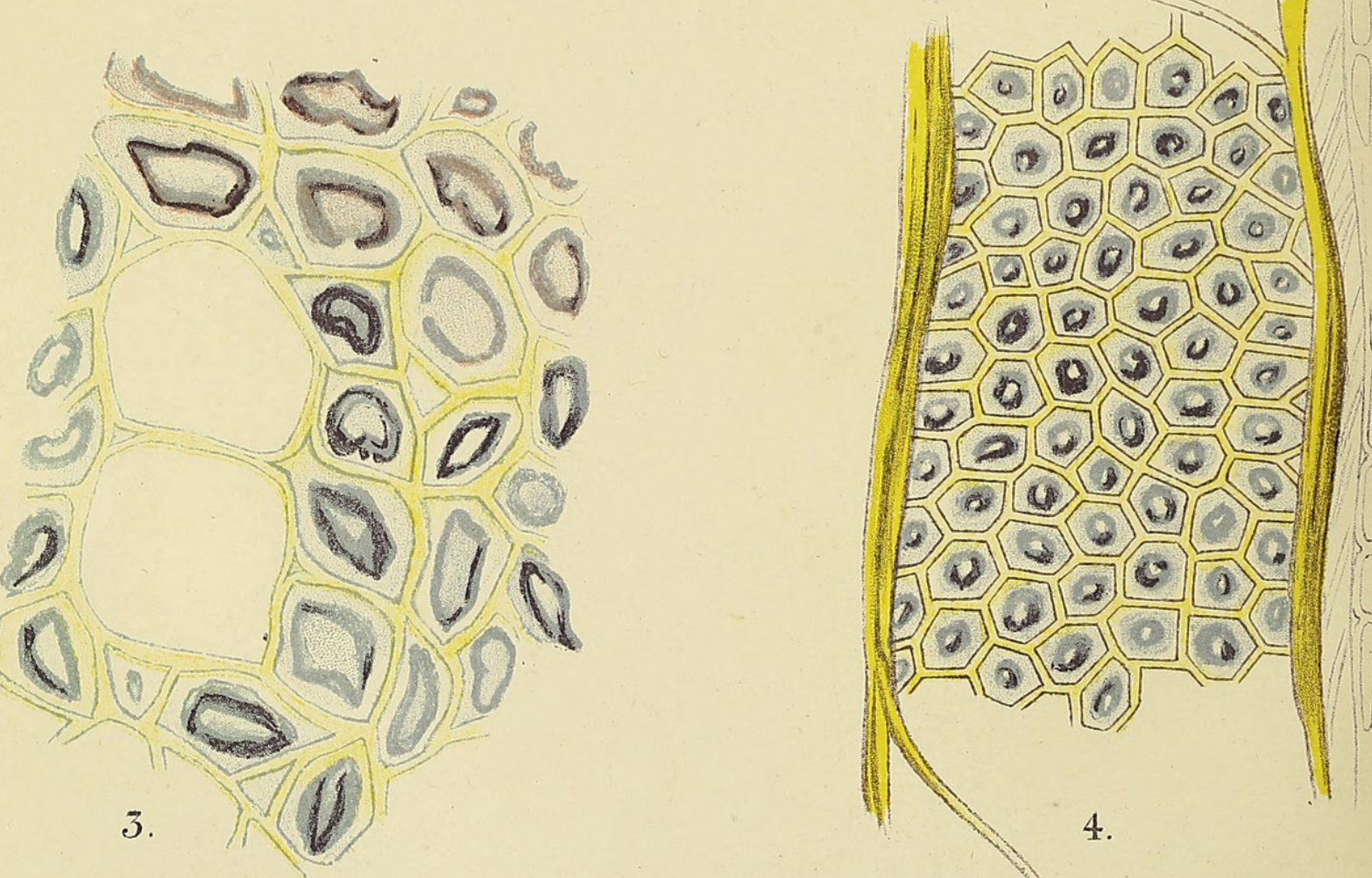

4. 


\section{$2 \mathrm{BHL}$ Biodiversity Heritage Library}

Potter, Michael Cressé. 1904. "On the occurrence of cellulose in the xylem of woody stems." Annals of botany 18, 121-140.

https://doi.org/10.1093/oxfordjournals.aob.a088947.

View This Item Online: https://www.biodiversitylibrary.org/item/234469

DOI: https://doi.org/10.1093/oxfordjournals.aob.a088947

Permalink: https://www.biodiversitylibrary.org/partpdf/318748

\section{Holding Institution}

Smithsonian Libraries

\section{Sponsored by}

Biodiversity Heritage Library

\section{Copyright \& Reuse}

Copyright Status: Not in copyright. The BHL knows of no copyright restrictions on this item.

This document was created from content at the Biodiversity Heritage Library, the world's largest open access digital library for biodiversity literature and archives. Visit BHL at https://www.biodiversitylibrary.org. 